\title{
Problems and Countermeasures in Primary School English Picture Books Teaching --based on the study of P Primary School in northwestern China
}

\author{
Kaiyuan YANG \\ School of Teacher Education \\ Nanjing Normal University \\ Nanjing, China \\ YANG Xuan \\ Lanzhou Oriental School \\ Lanzhou, China
}

\begin{abstract}
The pictures books are made of a large number of coherent, colorful drawings and relatively few, simple and easyto-learn texts to present the story and convey it to the reader. However, as a novel teaching material introduced in China, the efficiency of its use cannot be effectively guaranteed. This survey, considering the domestic status quo of English teaching, carries on the regional study of English picture books to provide some suggestions for improving the efficiency of its use in the English classroom in primary schools. The experiment takes the third-grade students and their parents, and English teachers at a primary school in western China as the subjects. According to the data from questionnaires, interviews and classroom observation and transcripts, it is found that teachers should make improvements in material selection, teaching and evaluation, so as to promote the formation of the core competence of English to prepare for long-term development.
\end{abstract}

Key words: English picture books; English teaching in elementary school.

\section{Introduction}

English, as one of pivotal subjects in compulsory education, is impacted by manifold factors. Learning English can better ground for learners' personality and ability and for their future development. English Curriculum for Chinese Primary Schools and Junior/Senior Middle Schools (Curriculum) regards the learning interest, attitude and confidence as the prerequisite of English teaching and the forming of learning strategies and sound character as the important part of curriculum objective (Curriculum:4). It also demands teachers to enrich the course resources to expand English learning channels.

The picture books, as one of the resources, hold various language materials and profound wisdom, being adopted by English teachers to cultivate students critical thinking, cross-culture awareness, imagination, learning ability, etc. The Curriculum enumerates that pictures paly the key role in listening, speaking, reading and writing. Students need to practice the four skills with the help of images (Curriculum:12-17).

\section{Literature review}

\section{Important definitions}

\section{Picture books}

Picture books has been developing its status gradually, originated from Europe in $17^{\text {th }}$ century, introduced to and popularized in the United States in 1930. As for Asia, it first emerged in Japan, and in 1960s, it was imported to Taiwan, after which it becomes popular in the mainland of China.

Picture book has no exact and absolute definition. Tadashi Matsui(1997), the father of modern picture books in Japan, regards the picture book as the art of a combination of language and pictures in a way of re-creation and visualizing as the material form of books, keeping its traits so as to evoke readers' curiosity Hao Guangcai deems that it is a book, adopting pictures to illustrate a story, or a story-like theme(2006:12). The Chinese writer, Peng Yi, explains that picture book is telling a complete story with the help of pictures and words simultaneously within about thirty pages, in big or small size(2013:14). Picture books are more appropriate for children and provide a novel platform for readers' imagination with the affiliate of pictures and words (Hu Yixi,2016:8). In a word, the author believes that picture book is a different text form adding visual effect to present a story vividly, in which the text and illustrations are fairly important. 


\section{English picture books}

After being promoted and updated by creators from different countries, picture books have been produced and translated into various languages. English picture books are supplementary for English learning, which are designed for children who have limited language proficiency to enjoy reading. Generally, they attractively have vivid plots, comprehensive themes and authentic language (Wang Pan, 2018:6).

As Smallwood (1998) pointed out, there are eight characteristics of the picture books. First, the themes, topics or storylines are appropriate to the age of the learners. Second, the main characters are similar in age or older than the learners and descriptions of characters are simple and clear. Third, the plot is simple and straight-forward. Fourth, the sentence patterns are simple and mostly controlled. Fifth, the use of dialogue is realistic and there is limited use of unfamiliar language and experiences. Sixth, rhyming is included as it aids memorization and it is useful in language learning. Seventh, the books are well-illustrated. Then, the reader is able to understand the story just by looking at the pictures.

English picture books are in possession of obvious advantages over other reading materials because they make learning full of simplicity and pleasure with the help of intelligibly meaningful contents and well-illustrated pictures.

\section{The teaching of English picture books}

English course is of instrumentality and humanity. Firstly, it is used to cultivate English competency. Students can grasp basic English language knowledge and obscure language skills. At the same time, it is aimed to broaden horizons and enrich living experiences to arouse their intercultural awareness and form positive characters and world view.

English picture books are accordant with the nature of English course. On the one hand, they are tools or auxiliary reading materials through which readers can learn English words and grammars in or after the class. On the other hand, with the help of authentic language, readers can know more about foreign lifestyle, culture and custom, and when they are reading, they subconsciously wonder or compare cultures at home and abroad.

The English course is aimed to establish comprehensive language use ability basically, improve psychological and intellectual development and humanity quality. And the general objective comprises five offshoots: language skills, language knowledge, affective attitude, learning strategies and cultural awareness, according to which there are total five levels in compulsory education. Level 1 is designed for the starting grade, which requires students to be curious about English and be interested in foreign culture (Curriculum:10). As for language skills, pictures play the exceptional role in reading and writing, which are shown in the following table.

\begin{tabular}{|l|l|}
\hline Reading and writing & Students are able to \\
\hline & $\begin{array}{l}\text { look and read. } \\
\text { read the words after acknowledging the objects. } \\
\text { read and understand simple story with the help of pictures. }\end{array}$ \\
\hline
\end{tabular}

Table 1. The criteria of language skills level-level 1

In primary school, English classes are replete with intriguing games to develop students' curiosity and interest so as to complete the teaching tasks. The desire for playing is a congenital nature of children, if they can learn and have fun at the same time, the study will be more constructive. As teaching materials, their vivid words, visual pictures and the joint effect are utilized by teachers to arouse students' interest and motivate the learning atmosphere in English teaching. Teachers have to select appropriate contents based on students' cognition and ability to help students grasp elemental vocabulary and language knowledge and understand the implicit themes, which is a complicated and demanding task for teachers to display the value of picture books.

\section{Theoretical basis}

\section{Piaget's theory of cognitive development stages}

Cognition is deemed as a process of information process, or mental process, including the producing, attention of working memory, and comprehending language, learning, reasoning, decision making and problem solving.

Piaget believes that children have different ways of thinking from adults, and even among children of different ages, there is still some differences because intelligence grows and develops through a series of stages. In Piaget's view, the mind is dynamic and cognitive development involves changes in cognitive process and abilities. 
There are total four stages of children's cognitive development, low-grade students in primary school are at the Preoperational Stage(https://www.verywellmind.com/piagets-stages-of-cognitive-development-2795457), and they begin to think symbolically and learn to use words and pictures to represent objects, while they are getting better with language and thinking, they still tend to think about things in very concreteterms.Therefore, picture books used in low grades in primary schools concur with students' cognitive development and can help them learn language and develop critical and logical thinking.

\section{The input hypothesis}

The input hypothesis, consisting of four aspects, is the nucleus of The Monitor Theory proposed by Krashento expound the process of the second language acquisition (Krashen, 1985).

Comprehensibility the means the forms and contents of input language must be understandable and it is the prerequisite of language learning and acquisition. Compared with traditional textbooks, picture books with graphics and words are much more comprehensible.

Input must contain " $i+1$ ", which means the language that exposed to learners should be within and also beyond their schemata so that they can understand most of it but still feel difficult (Rod Ellis,1999). With the help of pictures, learners can understand most of the contents, but there are still some important points that need to be explained and prompted, such as the themes, details and unknown vocabulary.

Krashen believes that the input language must be authentic, meaningful, interesting as well as relevant. There is a great need to process the meaning of language to guarantee beneficial acquisition because genuine and intriguing context can facilitate language acquisition. Picture books, presenting attractive stories derived from real life with colorful graphics and simple words, make learning much easier to satisfy the intention of learners at low grade in primary schools.

To accomplish language acquisition, there should be continuously sufficient input. The picture books can be a supplement to current textbooks used in primary school, and the subsidiary resources can make sure the constant English input of learners at school or home.

\section{Schema theory}

German philosopher and psychologist Kant first put forward the concept of schema in the category of cognitive science. In his opinion, schema means the linkage of concept and the perceived object (Xiang Ningshuang, 2015:54). Learners can link the prior experience and knowledge, the current knowledge, and conceptual thinking to form the new one (Wang Jie,2017:20). F.C. Bartlett, a renowned English psychologist in the 1920s, develops the concept of schema in depth, which dynamically reflects and organize one's historical experience. Knowledge is restored in brains with the assist of schema, so it also means the cognitive mode of knowledge (Li Xia,2019:14). Schema is the foundation of cognition, which can reconstruct, understand and memorize the obtained new information. Rumelhart (1977), a representative of this theory, focused on language learning and pointed out that meaning is not conveyed by reading materials, but is constructed by readers based on their existent knowledge schema, and reading material can only be regarded as the guidance or auxiliary.

There are total four characteristics of schema (Wang Jie, 2017). Firstly, in our brain, schema is stored hierarchically. A scheme is made up of multiple lower-level forms, which can comprise higher-level schema. Secondly, there are miscellaneous information in the schema, which can show all kinds of our life experience abstractly so that it can illustrate diversified events or scenes of life. Thirdly, the unit of schema is variable because of existing knowledge and new information, and the schema is organized orderly by knowledge. Moreover, Schema predicting the development of events.

As Schema theory implies, reading comprehension is a process of dealing with new information, in which there is interaction between new information and the existing knowledge. Reading materials are bridges for readers to construct the meaning, so learners' active participation and understanding are quite significant for them to acquire new knowledge. Primary school students are in the preliminary as well as critical period of learning English because they have to absorb and store manifold schemas for future learning. Picture books are more intelligible, and they are the media that enrich and activate schemas of various topics in learners' mind.

\section{Methodology}

Although picture books are quite important for the learning of primary students, they are not paid enough attention in English classes. Therefore, this paper mainly attempts to answer the two questions about Jigsaw teaching:What the status quo of the teaching of picture books? How can English teachers take good use of English picture books? To answer the two questions, the author utilized questionnaire, interview, class observation and classroom recording. The subjects in this experiment are fifty students at grade three, twenty English teachers and ten parents from one of advanced primary schools in the northwestern China. 


\section{Data collection and analysis}

\section{Questionnaire}

It consists of four parts: the important points of English class in primary school, the function of English picture books, its status and using frequency, and it is used for to get the information about relevant opinions of English teachers and the status quo of the teaching of English picture books in low-grade class.

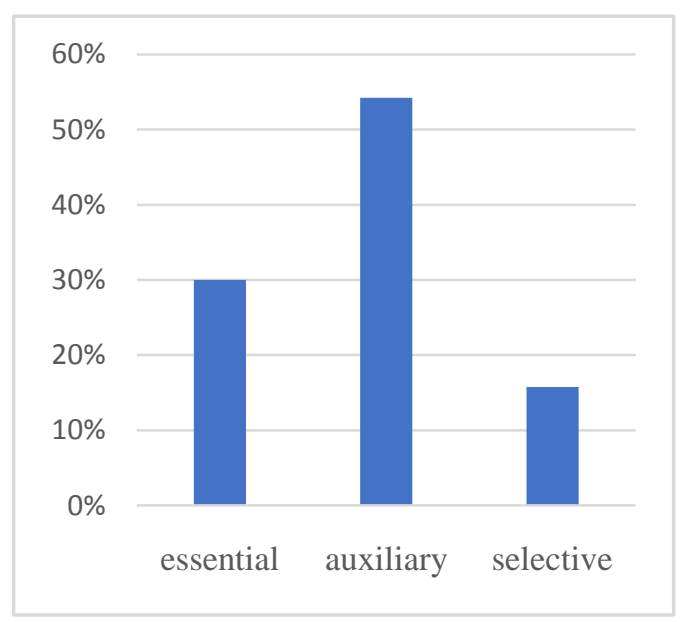

Figure 1. Important teaching points

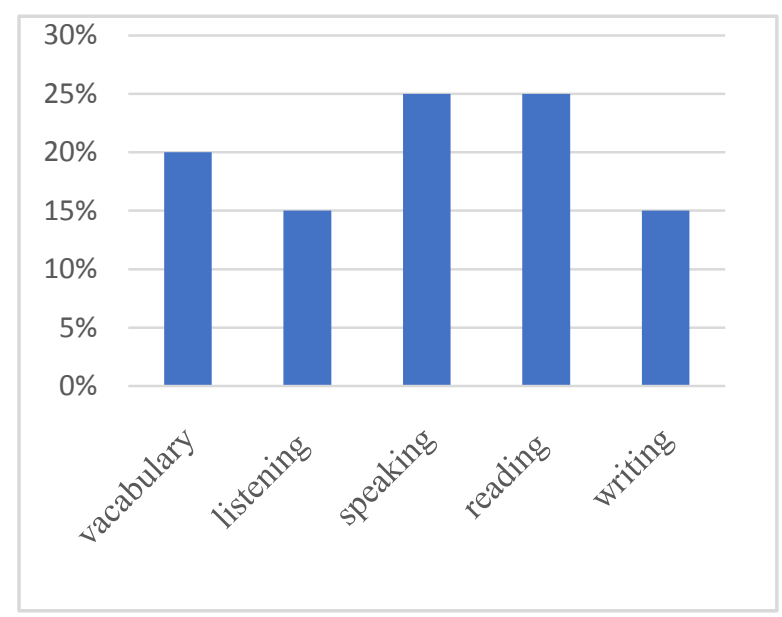

Figure 2. The function of picture books

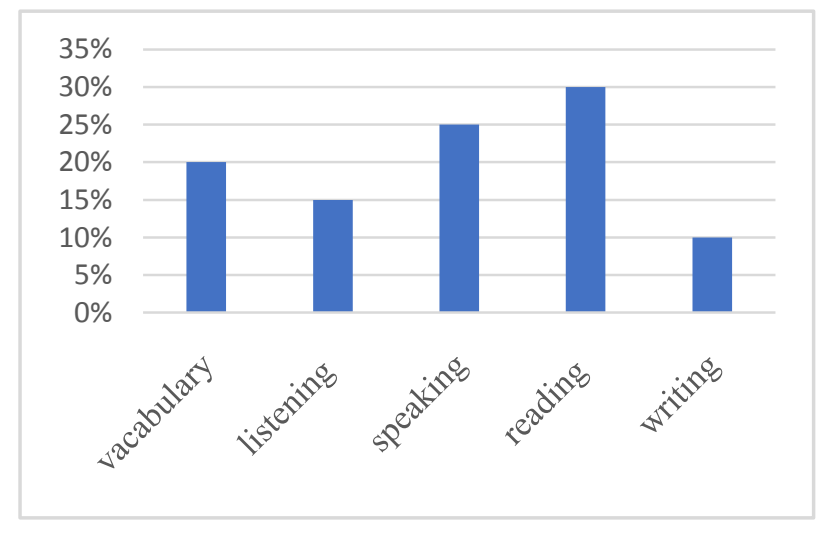

Figure 3. The status of picture books 


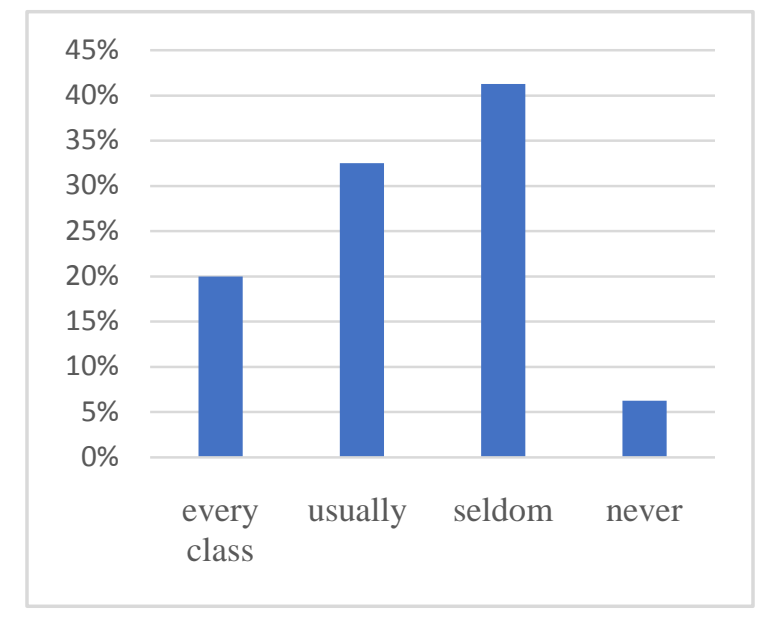

Figure 4. The using frequency of picture books

According to the above charts, teachers in the experiment school think the most important points of English teaching in primary school are developing students reading and listening ability, and the function of picture books are quite beneficial for teachers to cultivate students long-term learning ability and language proficiency.30\% teachers believe that it is essential to use such teaching materials in class.

According to the above charts, teachers in the experiment school think the most important teaching points of English teaching in primary school are developing students reading and listening ability, and the function of picture books are quite beneficial for teachers to cultivate students long-term learning ability and language proficiency. $30 \%$ teachers believe that it is essential to use such teaching materials in class. Although the picture books have great functions and important status, it's use frequency is not ideal, which means their potential are not being achieved.

\section{Interview}

The author conducted an interview among parents of the experiment class to know about their knowledge, attitude and the learning situation of their children.

Considering the feasibility of the experiment, the authors conducted the interview on a random sample of 10 parents. According to the interview, the response of parents is much more positive.All the parents give the priority to children's learning interest, although they have limited knowledge of picture books, they believe the words and pictures are useful for arousing children's learning interest and motivation. Their children have great interest in picture books, and they usually read at schools or institutions but seldom read at home. Therefore, they think there is great need to take use of pictures books. Parents also give constructive suggestions to the improvement of English pictures. Firstly, they should be more comprehensible and vivid with ample themes. Secondly, they should be more suitable for children and close to their daily life. Then, they should be accompanied by recordings, which can train children's listening and speaking ability.

\section{Class observation and transcripts}

After getting the permission of the English teacher, the author took 2 months to observe the students' performance and teaching method in classes of picture books to obtain more details and recorded some videos of the classes to make clear the teaching steps in each class and then find out the merits and potential problems. The following are the teaching steps of one class dealing with English picture books, which was proofread by teachers for several times. The supplementary teaching material is the Unit Four-We love animals, which is from the the edition published by the People's Education Publishing House.

Unit 4 We love animals

Teaching procedures

1. Greetings

Greet with students and ask students some questions: How are you today? How's the weather like today? How many seasons are there in a year? And who are they? How many days are there in a week? And who are they?

\section{Lead-in}

Sing a song about animals sounds together.

3. Duty report

Invite the duty reporter to dub the movie video cut about Zootopia.

4. Presentation

What animals do you like? Invite some students to answer. Listen

84 
Play the voice of some animals and let students guess what's this?

Students will give the answers. It's a/an.

Write down these words: cat, dog and sheep

Practice what color is it. It's

Then use the whole sentence: It's a purple cat.

Introduce some animals' sounds in English way.

Read the chant together:

cat cat, meowmeowmeow

sheep sheep, baa baabaa

dog dog, wolfwolfwolf

Look

Show some animals' pictures covering the main body, let students guess what's this? It's a/an

Write down these words: bear, frog and horse.

Practice what colour is it. It's

Then use the whole sentence: You can see, it's a brown bear.

Act

Invite one student come to stage. Tell him/her an animal, then let he/she act like the animal. Let other students to guess what this is.

Write down these words: bird, duck, fish and monkey.

\section{Guess}

Show some animals' riddles and let students guess what it is and write these animals on the blackboard.

What animal wears big black glasses on its face.

I am very big and heavy. I have a long nose and big ears. Who am I? I have a very long neck and legs. I can eat the leaves on top of the tree.

Practice and Production

I point, you say

Group work:

- What's this?

- It's a/an

- What color is it?

- It's

- It's a/an (color $)+($ animal).

Watch a video about the picture book. And answer what do you see.

Game 1 (Group work)

Play the game: brown bear brown bear, what do you see? Students point someone to say I see a XXX looking at me.

Game 2 (Group work)

Students practice the dialogue in freestyle. Using the pictures painted by them. Practice the sentences: XXX what do you see? I see XXX looking at me.

Protect the animals

Show a short video about hunting the polar bear. According to the video, let students know that animals are our friends. Please love animals.

Summary

Invite some students to sum up what they have learnt today.

Homework

Sum up what have you learnt today.

Write down other animals you known and make a song.

\section{Blackboard layout}

Unit 4 We love animals

cat dog sheep bear frog - What's this? - It's a/an....

horse bird duck fish monkey - What color is it? - It's ....

panda elephant giraffe - What do you see? - I see ....

\section{Conclusion}

After two-month experiment, through the investigation and observation, the author finds there exist quite a lot of problems when teaching English picture books. Therefore, to address those problems, the author provides some methods to improve the use of English picture books.

\section{The choice of teaching materials}

The most pressing point I that English teacher should notice the importance of picture books. 
Althoughthe school can exploit school-based courses and the teachers can choose the resources, the credibility of the choice cannot be guaranteed. If the choice is inappropriate, the quality of the course will be affected significantly. The choice of teaching materials includes types, contents, themes, editions and so on, and it should be student-centered, which requires the teacher to consider students' cognition, personality, proficiency, interest and habits.

Wang\&Chen (6-8) promote that English reading is quite imperial for learners' language fulfillment, and they perfect the branches of reading literacy for Chinese students. According to their proposed Grading Standard (4351), preparatory stage, stage one and stage two are for students at early grades in primary school, which are the best time to enlighten reading, so the teachers and parents have to choose the reading materials carefully and meticulously. The reading materials at the three grades are similar to some extent. First of all, simple and highfrequency words and sentences are preferred. Next, nursery rhymes, fairy tales, traditional stories, real-life stories which contain sense of rhyme, simple contents and plots, moral themes in the way of description. Furthermore, the cards and picture books are thought the best types. Therefore, parents and teachers can deliberately choose picture books based on this grading standard.

\section{The teaching of English picture books}

The picture books are made up of resources, but in some classes, the teacher did not exploit the materials in depth, which could not help students truly understand and uptake the content.

Firstly, the picture books are the multimodal discourses, so English teacher should make good use of pictures, words, recordings to teach language knowledge and train students' language skills. There also should be a balance among these elements in different classes. Meanwhile, the cultural elements bedded in pictures and texts should not be ignored, which means the teacher should cultivate students' cultural awareness. Secondly, learning interest is the prerequisite for learning, so the teacher must know about students' preferences and design multiple activities to engage students in class. Especially group activities, which can reduce their anxiety and learn to solve problems with different partners. Thirdly, "continuum task" created by Wang Chuming(2012) can help students practice the knowledge into new tasks, which is a good way to test their learning results. The teacher can design speaking and writing activities after the learning of picture books to nurture students' creative ability. And the teacher can utilize think-aloud method to encourage students to speak aloud their thoughts when reading the picture books.

\section{The evaluation of learning}

The author noticed that in most classes, the teacher spent less than twenty minutes on picture books. She guided students to read some pages and then focused on the textbook. There were no valuable output activates to evaluate the input and intake of the content, and the teacher seldom evaluated students' learning results. Therefore, teachers should redesign the time allocation to each step. After learning the story, students are supposed to engage in practices and output activities to develop language skills and in various evaluation activities during and after the class. The teacher can assess students' understanding and learning of the objectives through the lessons. Moreover, students can be required to record the content of the picture books after school, thus parents can be involved in the evaluation stages.

The picture books are characterized by colorful pictures, rich and simple contents, and meaningful themes, which can be an auxiliary tool to provide authentic context and broaden children's horizon. Therefore, there is a great need for teachers pay more attention to its use. At the same time, teachers should focus on the choice, teaching and evaluation steps to utilize English picture books to a better extent.

\section{References}

Hao Guangcai (2006). Hao Hui Ben Ru He Hao. Nanchang: $21^{\text {st }}$ Century Publishing Group.

Hu YIxi (2016). Our primary school English picture books coaching present situation analysis and countermeasure research, M.A. Thesis. Wuhan: Central China Normal University.

Krashen,S.D.(1995). The input hypothesis: issues and implications. London: Longman.

Matsui, T. (1997). My Theory on Picture Books. Changsha: Hunan Children's Publishing House.

Peng Yi (2013). Tu Hua Shu Ying Gai Zhe Yang Du. Nanchang: Jieli Publishing House.

Rod Ellis (1999). Understanding second language acquisition. Shanghai: Shanghai Foreign Language Education Press.

Rumelhart, D.E. (1977). Toward an Interactive Model of Reading Attention and Performance. New York: Academic Press.

Smallwood, B.A. (1988). Children's Literature for Limited English Proficient Students, ages 9-14. [Online] Available: https://eric.ed.gov/?id=ED356647 (April, 1988).

Wang Chuming(2012). Continuum task--an effective way to improve foreign language learning efficiency. Journal of Foreign Language World, 5, 2-7. 
Wang Jie (2017). An experimental study on the effects of reading English picture books for lower grade pupils, M.A. Thesis. Ganzhou: Gannan Normal University.

Wang Pan (2018). A study on the application of English picture boos in primary school lower-grade students' reading class, M.A. Thesis. Wuhan: Central China Normal University.

Wang Qiang, Chen Zehang (2016). The standard of leveled reading for Chinese Primary Schools and Junior/Senior Middle Schools. Beijing: Foreign Language Teaching and Research Press.

Xiang Ningshuang(2015). Cognitive research on vocabulary teaching to English majors. Beijing: National Defense Industry Press.

English curriculum for Chinese Primary Schools and Junior/Senior Middle Schools. 2011.Beijing: Beijing Normal University Publishing Group.

https://www.verywellmind.com/piagets-stages-of-cognitive-development-2795457 